\title{
Accounting for Bitcoin and Other Cryptocurrencies under IFRS: A Comparison and Assessment of Competing Models
}

David Procházka. University of Economics in Prague. Czech Republic prochazd@vse.cz

\begin{abstract}
The invention of blockchain technology has radically changed the perception of how monetary systems can be structured and operated. Central banks and state authorities mostly refuse to acknowledge that cryptocurrencies are money, yet the number of payment transactions using cryptocurrencies is increasing and cryptocurrencies form a non-negligible stake of wealth. As with other economic phenomena, cryptocurrencies shall be addressed in the financial statements of the entities using them, albeit without any accounting guidance in current financial reporting standards. This paper fills this void by suggesting, comparing, and assessing potential accounting models under IFRS. Based on evidence from literature review, as well as recent time-series data on the price volatility of cryptocurrencies, the paper shows that fair value accounting is the most relevant source of useful information for users of financial statements when cryptocurrencies are acquired for investment purposes. Furthermore, the paper identifies scenarios under which cryptocurrencies shall be treated as (foreign) currencies, even though financial system regulators do not consider cryptocurrencies as being money (fiat currency).
\end{abstract}

Keywords: IFRS, Bitcoin, Cryptocurrency, Accounting, Volatility, Fair Value

\section{INTRODUCTION}

The invention of blockchain technology has radically changed the perception of how monetary systems can be structured and operated (Nakamoto, 2008). The traditional fiat monetary systems boast many advantages (Shi, 1997) and will 
surely dominate in the near future, though Bitcoin, and other cryptocurrencies built up as decentralised cash systems provide economic agents with alternative payment channels featuring unique qualities. The growing on-line business no longer has to rely solely on financial institutions as trusted third parties. Electronic payments can be processed without any central authority stepping in to mediate the transaction and guarantee its authenticity. The main advantage of a cryptocurrency, which distinguishes it from the traditional concept of money, is how security and verifiability is ensured. A cryptocurrency is nothing less than the result of a cryptographic computational proof of the chronological order of transactions in the form of a peer-to-peer distributed timestamp. Cryptocurrency is, thus, a chain of digital signatures and the system is secure as long as honest nodes collectively control more $\mathrm{CPU}^{1}$ power than any cooperating group of attacker nodes (Nakamoto, 2008).

The primary intention of blockchain development was not to create a new currency, but to establish the principles of a functional decentralised cash payment system (Rosic, 2017). The cryptocurrency which arose was a by-product, serving as a medium of exchange and this is the essential function of money (Kiyotaki and Wright, 1989), but not the only one. Ten years after its release, economic agents are acquiring cryptocurrencies not only with the view to processing online cash transactions, but also to investing and realising future capital gains. Cryptocurrencies meet the second function of money, "store of value" (McCabe, 1989; Ram et al., 2016). As with other new investment assets, prices are highly volatile and subject to steep increases and rapid declines. Furthermore, their intangible (digital) nature raises serious doubts about their real (intrinsic) value and boosts, thus, the magnitude of price fluctuations.

Regardless of what their real value is, cryptocurrencies form a non-negligible stake of wealth. The server Coinmarketcap.com listed 1,335 cryptocurrencies with a total market capitalisation of $\$ 572,573,375,760$ at the end of 2017 . During some price peaks, the combined total market capitalisation of cryptocurrencies was more than that of Google, which is the second largest company based on capitalisation, and was comparable with the GDP of Switzerland (Haig, 2018). The invention of cryptocurrencies can affect accounting as well. In particular, there are two streams of influence. Firstly, blockchain technology will probably

\footnotetext{
${ }^{1}$ Later, mining through graphic cards (GPU) replaced CPUs. At present, mining using ASIC chips is the most effective
} method. 
impact the way accounting transactions can be recorded and verified, e.g., by auditors. Secondly, cryptocurrencies are used by companies in their daily business and, as such, they should be accounted for and presented in financial statements. As with other new phenomena, accounting standard-setters are lagging in the delivery of accounting guidance. This paper focuses on the second aspect and its aim is to analyse and assess the competing accounting treatments of cryptocurrencies. The measurement models contained in International Financial Reporting Standards (IFRS) will serve as a starting point for the assessment. The appropriateness of each model will be discussed using the perspective of decisionusefulness and arguments based on the review of the relevant literature in related fields.

As the paper is conceptual, it is organised in a specific way. The Introduction describes the origin, nature and economic importance of cryptocurrencies. Section 2 presents several IFRS models of accounting treatment for cryptocurrencies, either as they reflect the opinions of public authorities on what cryptocurrencies are/are not, or as suggested by practitioners. These models are complemented with accounting policies which are identified by the analysis of IFRS. The analysis also exploits public pronouncements of state authorities, and opinions emanating from the community of cryptocurrency traders, miners, and other agents. Section 3 assesses the appropriateness of competing models, based on varying motives of cryptocurrency acquisition. The assessment is based on literature review. As research on the accounting aspects of cryptocurrencies is still in its infancy, pioneer studies in the field are combined with literature review dealing with the value relevance of fair value measurements and with the decision-usefulness of particular components of comprehensive income.

Professional literature and public opinions about cryptocurrencies revolve mainly around their technical features, whereas the paper's analysis of accounting treatments is evaluated with reference to their economic features. This approach, respecting the fundamental "(economic) substance over (legal) form” principle, produces interesting outcomes. In certain scenarios, a transaction involving a cryptocurrency shall be accounted for as a transaction in a foreign currency, despite the claim from central bankers that cryptocurrencies are not money. In the same way, it is shown that cryptocurrencies can not be recognised and reported as intangible assets despite their having a digital (virtual) form and regulators urging 
for such a treatment. In accordance with practice-oriented articles (Raiborn and Sivitanides, 2015; Tan and Low, 2017), the paper argues that faithful representation varies with reporting entities and depends on their actual business model along with the economic reality of the underlying transaction. Mining of cryptocurrencies shall, therefore, follow different accounting principles other than receiving payments in cryptocurrencies or investing into cryptocurrencies. To compare two main competing models, historical cost and fair value, the paper utilises the time-series analysis of the price volatility of cryptocurrencies. Section 4 concludes.

\section{COMPETING IFRS MODELS}

In IFRS, effective 1 January 2018, there is no reference regarding cryptocurrencies (further only CC or CCs). In such circumstances, a general procedure for the selection of an accounting policy applies. According to IAS8.10, management shall use its judgement in developing and applying an accounting policy, in the absence of IFRS, that specifically applies to a transaction, other event or condition. A selected policy shall result in information that is relevant to the economic decision-making needs of users and will be reliable. In making the judgement, management is restricted as it shall refer to, and consider the applicability of, the following sources in descending order (IAS8.11):

- $\quad$ the requirements in IFRS dealing with similar and related issues;

- the definitions, recognition criteria and measurement concepts for assets, liabilities, income and expenses in the Framework.

In determining an appropriate accounting treatment as described above, an entity needs to adhere to the fundamental principle of useful accounting information. To represent financial position and performance, it is not important which item an entity acquired, but why it was acquired. The purpose of acquisition and the expected use of the item within the entity is the key determinant of its presentation in financial statements. Take gold as an example. In the balance sheet statement of a goldsmith, gold will be presented as an inventory (either as material, or work-inprogress, or finished products). Contrariwise, in the balance sheet statement of a pension fund, gold will be reported within the investments. Finally, a coin dealer \& collector can hold gold both as inventory and investment. 
Theoretically, transactions related to CCs can be presented in financial statements ${ }^{2}$ as:

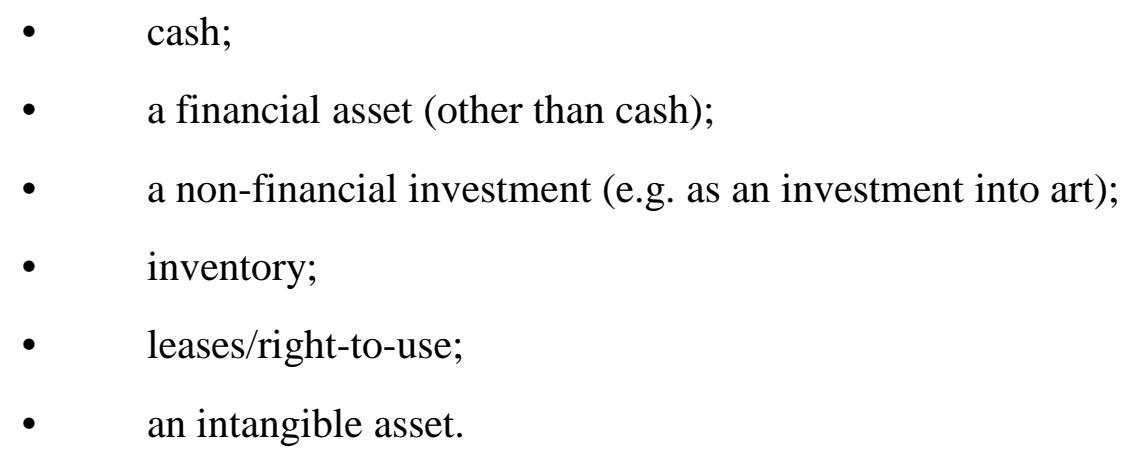

The following section analyses the conditions under which each treatment would be relevant, along with a description of the impact of respective policy on financial statements.

\subsection{Cash}

Cash is categorised as a financial asset under IFRS principles. A financial asset (IAS32.11) is any asset that is:

- cash;

- $\quad$ an equity instrument of another entity;

- a contractual right to receive cash or another financial asset from another entity, or to exchange financial assets or financial liabilities with another entity under conditions that are potentially favourable to the entity;

- a contract that will or may be settled in the entity's own equity instruments.

Unlike (Berchowitz, 2017), we can see certain settings under which CCs can be treated as cash. According to IAS7.6, cash comprises cash on hand and demand deposits. Unfortunately, this definition is just an enumerative list. There is no other attempt to define cash positively in IAS7 or in any other standards. Therefore, a general definition of cash (money) shall be used. The approach taken by (Berchowitz, 2017), i.e., a definition of cash in terms of legal tender is not entirely appropriate for two reasons. Firstly, legal tender (or fiat money) covers only one stage in the evolution of payment systems (Mishkin and Serletis, 2011),

\footnotetext{
${ }^{2}$ The paper excludes the case of business combinations, which is analysed e.g., by (Raiborn, Sivitanides 2015).
} 
which may be overcome by more efficient or secure systems (Greco, 2001). Secondly, treating cash as legal tender is a pure technical (legal) view which contradicts the fundamental principle of the economic substance over legal form (Framework 4.6). For this reason, a broader economic view shall be adopted for the definition of money. In economics, money is usually defined as anything that is generally accepted as payment for goods and services or in the repayment of debts (Mishkin and Serletis, 2011). CCs can meet such a definition. Moreover, (Mishkin and Serletis, 2011) admit that electronic payment technology can substitute for cash.

Using this economic exposition in accounting, CCs shall be presented in financial statements as cash if it is acquired in a business transaction as a medium of exchange, i.e., as a means of payment received for goods or services sold by an entity $^{3}$. IAS 21 shall be applied in such cases. Under current development, CCs are not generally accepted as a medium of exchange, therefore any payment received in CCs shall be treated as a transaction in foreign currency, translated into functional currency by applying a spot exchange rate at the date of the transaction (IAS21.22). Any holdings of CCs are monetary items, and, in preparation of financial statements, they shall be translated using a closing rate (IAS21.23a).

Certain communities process most payments in CCs. If an element of such a community is an accounting entity reporting under IFRS, it may happen, in exceptionally rare circumstances, that certain CC will became a functional currency of that entity. A functional currency is the currency of the primary economic environment in which the entity operates (IAS21.8). In that case, transactions not processed in CC (meeting the definition of functional currency) will be treated as a transaction in a foreign currency. However, it shall be stated that this is a hypothetical situation, as we are not aware of any such company at this point in writing.

\subsection{Financial asset}

Referring to the definition of a financial asset outlined in the previous subchapter, CCs do not meet the definition of a financial asset in the form of an equity instrument or a contractual right to receive cash. For that reason, three

\footnotetext{
${ }^{3}$ Expedia.com - an online travel booking agency; Overstock.com - an online retailer; Sacramento Kings - an NBA team are a few examples of companies accepting Bitcoin as a means of payment.
} 
measurement models defined by IFRS 9 (a financial asset at fair value through profit or loss; a financial asset at fair value through other comprehensive income; or amortised cost) are not directly available. However, the main motive for the purchase of CCs is based on speculation to realise future capital gain. This kind of a transaction does not fulfil the definition of a financial asset, but the economic factors surrounding the ("buy and hold") transaction are comparable to trading with financial instruments. Using the provision of IAS8.11, an accounting policy adopted for investment-like CCs can refer to the measurement models of IFRS 9. From applicable models, amortised cost cannot be employed, as CCs do not have any maturity date. Only FVPL or FVOCI models can be applied and shall be applied as a relevant source of useful information for the users of financial statements.

Both models require entities to remeasure financial assets at their fair values as at the reporting date. The main difference between the methods is geography where the gain or loss on remeasurement is reported within the comprehensive income statement. The first method prescribes the recognition within the profit and loss section (IFRS9.5.7.1), the second within other comprehensive income with a subsequent reclassification adjustment from equity to profit and loss (IFRS9.5.7.10). When selecting an appropriate model, the entity's business model test and the contractual cash flow test shall be performed (IFRS9.4.1.1). Their applicability to CCs is impossible, it can only result in the selection of an FVPL model. The sole application of FVPL approach may, however, not be fully appropriate under all situations. Therefore, the choice between FVPL and FVOCI can be done once again by setting one's own accounting policy. To justify the selection, it can be supported by the provisions of IAS 39 (the old standard on financial instruments replaced by IFRS 9). The wording of IAS 39 offers a better understanding of the differences between two basic investment horizons, when trading with financial instruments, than the terminology of IFRS 9.

According to IAS39.9, a financial asset at fair value through profit or loss is the asset which is classified as held for trading. A financial asset is classified held for trading if it is acquired or incurred principally for the purpose of selling or repurchasing it in the near term. Furthermore, available-for-sale financial assets are those non-derivative financial assets that are designated in such a way, i.e., 
they are acquired to realise capital gains in the remote rather than in the near future (i.e., without a short-term speculative motive).

Finally, it shall be pointed out that CCs can fall within the scope of IFRS9 if they are recognised as (any kind of) assets and are designated under hedge accounting as a hedged item (IFRS9.6.3.1), supposing they are reliably measurable (IFRS9.6.3.2). Similarly, transactions with CCs may directly fall under IFRS 9 when short-selling CCs and other derivative-like contracts, such as CFDs (Contract for Difference), margin trading, or liquidity swaps.

\subsection{Non-financial investment}

As CCs do not meet the exact definition of financial assets, they can be treated in the same way as non-financial investments (e.g., art, gold coins, investment gold, etc.). Once again, non-financial investments are not regulated by any specific piece of IFRS ${ }^{4}$ and entities shall develop their own accounting policy. In practice, two methods prevail. Firstly, a conservative historical cost (HC) model, under which an investment is measured at its acquisition cost, tested for impairment at year-end, and any holding gain is realised and reported in the income statement once the asset is sold. Secondly, the FVOCI model is applied with continuous recognition of unrealised gains and losses under other comprehensive income. The HC model is preferable when the current market value of the investment is not reliably determinable. This is the case, e.g., for (most) art which is unique, and its true market value can be uncovered only upon sale. Non-financial investments are purchased to invest money in the long-term and investments in CCs shall be treated within this category only if the purchase is not driven by short-term speculation. As the market value of CCs is readily available, FVOCI is a more relevant measurement model. Under such circumstances, the similar treatment of CCs as non-financial investments will produce the same outcome as their treatment for an available-for-sale-like financial instrument.

\footnotetext{
${ }^{4}$ Except for some indirect guidance for gold, which is considered as a commodity by IFRS9. B. 1.. If it does not fall under the scope of IAS2 as inventory/commodity (either at lower of cost or net realisable value at fair value less cost to sale in the case of a trade-broker), or under IAS 21 as a currency (Sullivan, 2016), then an entity-specific accounting policy shall be developed especially for speculative and long-term investments into gold.
} 


\subsection{Inventory}

Two scenarios, leading to the recognition of CCs as inventory can be identified. Firstly, an entity may purchase CCs in order to resell them to its customers. In this case, CCs shall be similarly treated as merchandise or as a commodity held by broker-traders. Broker-traders are those who buy or sell commodities for others, or on their own account, and such inventories are principally acquired with the purpose of being sold in the near future to generate a profit from fluctuations in price or the broker-traders' margin (IAS2.5). Despite there being no exact definition of commodities under IAS2, their description corresponds to the economic model of Bitcoin and other CC brokers and this model is more relevant and reliable compared to merchandise by CC brokers. CC brokers provide the investors with an alternative OTC platform to buy and sell CCs rather than directly via a regular exchange (Buntinx, 2017), meeting, thus, a condition of IAS 2 for broker-traders to buy or sell commodities for others. Regarding the measurement, IAS 2 presumes that commodities are mainly measured at fair value less costs to sell and changes in fair value less costs to sell are recognised in profit or loss in the period of the change (IAS2.3b). The required measurement model is close to the FVPL model analysed in Chapter 2.2 (the only difference is in deduction of cost to sell under IAS 2) and produces comparable results regarding income statement. The comparability of both models is important, as it may be difficult, in practice to distinguish whether an entity acts as a broker to buy or sell CCs on its own account (IAS 2 guidance), or whether trading is made for the purpose of selling or repurchasing it in the near term (IFRS 9 guidance).

The accounting treatment of purchased CCs for brokering purposes does not constitute any serious difficulties. The mining of CCs is a more interesting and sophisticated case. The production process is shown in Fig. 1.

It must be noted that CCs do not emerge directly, rather they are created as a byproduct of (reward for) the verification of electronic transactions waiting in the public ledger, called the blockchain. As with any other ledger, the blockchain requires chronological order which is accomplished by collating the recent transactions into blocks. 


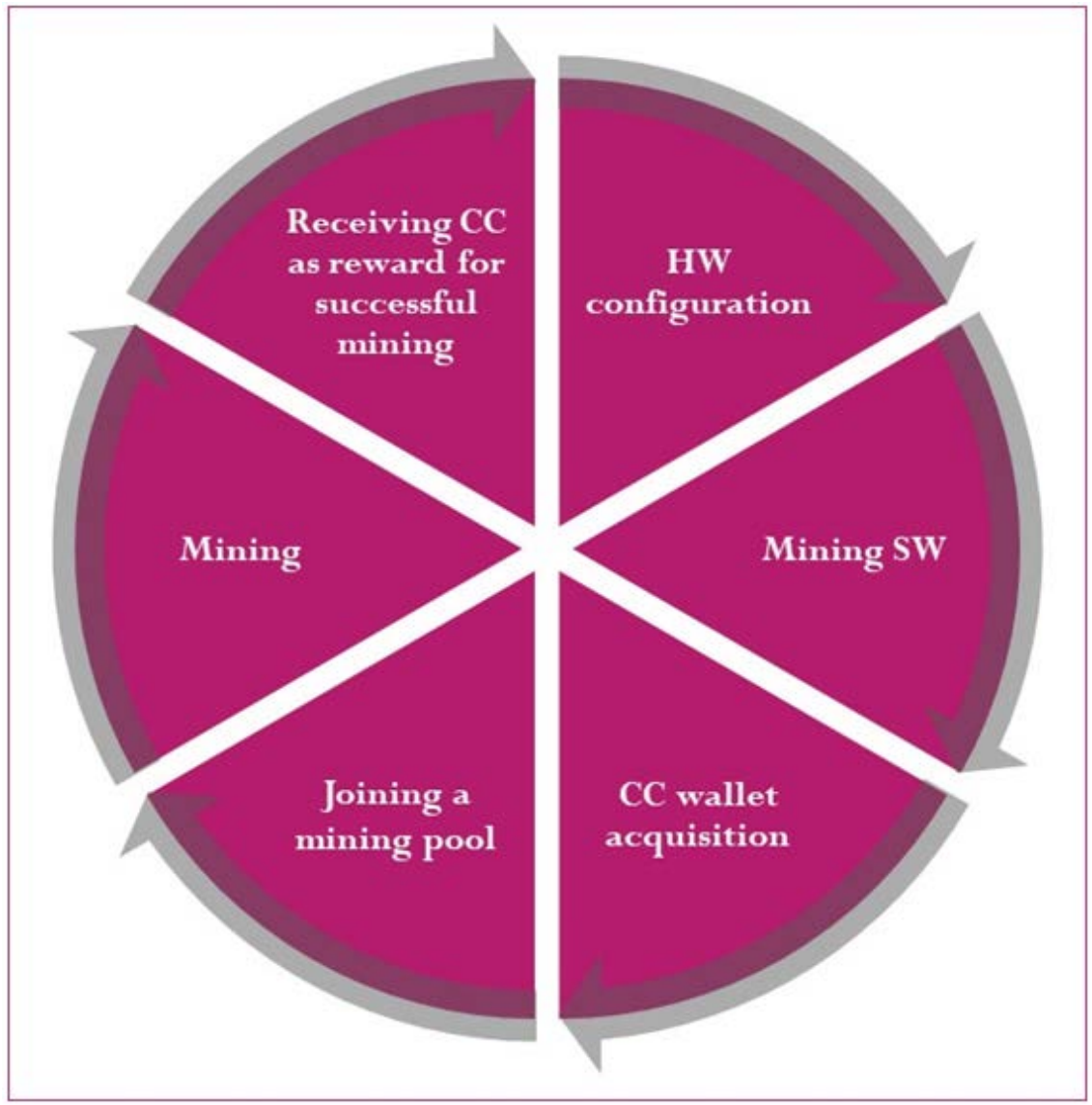

Figure 1. Process of cryptocurrency mining

Each transaction is agreed by a decentralised network and such verification requires every block included in the system to comply with publicly known cryptographic rules (currently specific "scrypts" or SHA256 hash verification processes are used). The creation of a new block requires solving a cryptographic task by finding a number, which is combined with data in the block through a hash function and produces an output complying with the announced rules. The resulting number is included in the block and combined with the previous blocks, which prevents any subsequent modification of already verified blocks, as it would invalidate all blocks yet to be validated (D’Aliessi, 2016).

The level of encryption rules out the possibility that outputs can be predicted. To find a correct number to verify data in block, it has to be guessed. In practice, such a guess can be done only by using the computational power of modern computers. Therefore, a miner must have suitable hardware. HW parameters 
influence how fast the encryption can be resolved as well as the consumption of electricity. Furthermore, mining software must be acquired. The mining SW connects a miner to the blockchain or to its mining pool if the miner decides to mine in cooperation with other miners. Once the mining is successful (the number conforms to the hash function and the block is verified), the winning miner (or mining pool) receives a reward for the verification of the data in block in the form of the given CC. Received CCs are stored in the miner's wallet which may be in an electronic, software, online, hardware, mobile, or paper form (Acheson, 2018).

Regarding the accounting treatment of CCs acquired by mining, IAS 2 guidance on the cost of conversion shall be applied ${ }^{5}$. The cost of inventories shall comprise all costs of conversion incurred in bringing the inventories to their present location and condition. The costs of conversion of inventories include costs directly related to the units of production as well as a systematic allocation of fixed and variable production overheads that are incurred in converting materials into finished goods (IAS2.11). Electricity and labour costs (if any) directly related to the mining are the main examples of direct costs. Indirect production overheads will be formed by depreciation of hardware and mining software, depreciation of the mining "factory" (if any) and other mining equipment (e.g., fans to cool the spaces), wages of programmers and service workers, etc.

When determining production costs, IAS2.13 requires the allocation of fixed production overheads based on the normal capacity of the production facilities. Normal capacity is the average production over a number of periods under normal circumstances, taking into account the loss of capacity resulting from planned maintenance. However, there is no normal capacity in the production of CCs, as mining is a competition in which the winner takes all. The exact production of a miner depends on its computational power relative to the power possessed by other miners. The first miner to get a resulting hash for a given block announces its victory to the rest of the network. All the other miners immediately stop work on that block and start trying to find the encryption for the next one (Acheson, 2018). The question is how to account for costs incurred during unsuccessful mining conquests. Such costs can be regarded as wastage and shall be therefore

\footnotetext{
${ }^{5}$ Despite the fact that mining is run mainly by individuals or pools of individuals, there are also a few companies engaged in mining, such as Bitfury or KnCMiner, bankrupted in 2016 (Higgins, 2016). The biggest pool in the world, AntPool, is under control of the Bitmain company (Price, 2015).
} 
excluded from the acquisition cost and immediately expensed (IAS2.16a). However, as the processing of one block takes approximately 10 minutes (Acheson, 2018), any practical difficulty might be overcome by the immediate expensing of all production costs (as there is no material work-in-progress). The direct expensing of production costs will mean that CCs are measured at zero and an alternative measurement basis shall be used, but only in the case of a lasting possession. If the CCs mined are immediately converted to fiat money, the sale is recorded as revenue. If the CCs mined are held for future sales (at higher expected market prices), FVPL or FVOCI models shall be used for the measurement as in the case of their purchase.

In practice, some modifications to previous principles can arise. The mining of CCs is extremely competitive and miners can participate in two ways. Either on a stand-alone basis with irregular, but large pay-offs or by joining a mining pool, reducing, thus, the volatility in returns by receiving smaller, but more frequent, rewards (Madeira, 2017a). The establishment or the joining of a mining pool may constitute a joint operation as defined by IFRS 11. A joint operation is a joint arrangement whereby the parties that have joint control of the arrangement have rights to the assets, and obligations for the liabilities, relating to the arrangement. A joint arrangement is an arrangement of which two or more parties have joint control. A judgement, whether the membership in a mining pool meets the definition of a joint operation, depends on the method of distributing the block reward and the fees charged by the pool operator for managing the pool. The models of payment distribution depend on the assumption of risks between the miners and the mining pool operator (Madeira, 2017b). If the risk of unsuccessful mining is borne by the operator (i.e., payments to miners are done even if the block was not mined), the miner's reward for the contribution of its hashing power to the pool can be considered as a lease income (under the scope of IAS 17 or IFRS 16, if adopted earlier) and IFRS 11 is not applied. However, if the risk is assumed by the miners, the conditions of IFRS 11 for accounting for a joint operation may be fulfilled. The ultimate question is how to determine an interest in a joint operation. Once again, the construction of a payment distribution system can be helpful in this. ${ }^{6}$

\footnotetext{
${ }^{6}$ The two most commonly used models are the proportional model (based on the relative share of a miner`s hashing power contributed) and the "Pay Per Last N Shares“ (PPLNS) model. However, many other systems exist (Madeira, 2017b).
} 


\subsection{Lease/Right-to-use}

There is an alternative way to mine CCs. Cloud mining enables mining without HW and SW and without consuming electricity in the premises of the miner. Instead of direct mining, the necessary equipment, hosted at the premises of a provider, can be leased. Remote mining occurs in three main forms:

- Hash mining: a person/an entity sends their own HW to a provider; the provider is responsible for the configuration (SW), electricity, cooling, and other issues. Alternatively, HW can be also leased.

- Virtual hosted mining: a virtual private server is created, and one’s own mining software is installed.

- $\quad$ Leased hashing power: a specified amount of hashing power is leased; no physical or virtual computers are needed.

Most contracts last one year (Madeira, 2017c). Such contracts would be classified as operating leases under IAS 17. Under new IFRS $16^{7}$, a lease contract shorter than a year meets the "time-test" exemption from being recognised as a "right-touse" asset and a lease liability and the lease payment shall be allocated on a straight-line basis. Accounting treatment of leased equipment/hashing power for a period shorter than one year would, thus, have the same impact under IAS 17 and IFRS 16. If a contract is concluded for more than 12 months, IFRS 16 requires the recognition of a "right-to-use" asset and a lease liability on the lessee's balance sheet. Accounting treatment under IAS 17 would depend on whether the contract constitutes an operating lease or a finance lease. Regardless of which standard is applied, the cost associated with the lease will form an acquisition cost of the mined CCs, i.e., once the lease is accounted for, consumption of benefits will be treated under IAS 2 guidance, as described in the previous subchapter.

\subsection{Intangible asset}

State authorities and regulators (such as central banks) usually ${ }^{8}$ strongly disagree that CCs shall be treated as cash and that they do not comply with the (legal)

\footnotetext{
${ }^{7}$ IAS 17 is an old standard on leases effective until 2018, when it will be replaced by the new IFRS 16. Earlier adoption is permitted.

${ }^{8}$ An exemption to this practice can be demonstrated using the example of The Australian Senate, which admits that digital currencies should be treated as money for the purposes of the goods and services tax (Economics References Committee, 2015). Furthermore, Riksbank, the Swedish Central Bank, is considering launching its own cryptocurrency, e-krona, to deal with a massive decline in domestic cash use (Martin, 2018).
} 
definition of money (ECB 2015) ${ }^{9}$. As CCs are digital currencies, not having a physical form, some authors prefer to recognise CCs as an intangible asset on the balance sheet statement, with the cost model as a basic treatment and the revaluation model as an available alternative (Berchowitz, 2017). According to IAS 38.6, an intangible asset is defined as an identifiable non-monetary asset without physical substance. In a subsequent treatment, an entity needs to resolve two aspects - amortisation and measurement. Firstly, amortisation requires assessing whether the useful life of an intangible asset is finite or indefinite. An asset is identified as having an indefinite useful life when there is no foreseeable limit to the period over which the asset is expected to generate net cash inflows for the entity. This is the case of CCs, when viewed as intangibles. According to IAS 38.107, an intangible asset with an indefinite useful life is not amortised. There is an additional requirement of IAS 36.10 that an entity shall test such an intangible asset with an indefinite useful life for impairment annually, or whenever there is an indication that the intangible asset may be impaired.

Secondly, an entity may opt between cost model and fair value model for any subsequent measurement of intangible assets. Contrary to tangible assets under IAS 16, IAS 38 contains strict conditions, under which fair value model is allowed. A revaluation model can be applied only if fair value is determined by referring to an active market. Bitcoin and other major CCs comply with the condition of being traded in active markets. However, minor CCs suffer from a lack in trading activity and the condition is usually violated. This issue is further discussed in the final part of Section 3 which discusses the reliability of the fair value measurement in the context of CCs.

However, based on a previous analysis of economic reasons to acquire CCs, hardly any setting can be identified under which an entity would use and would be able to use CCs as intangible assets. Surely, CCs cannot be utilised in the same way as software, patents, or licences, neither it is a trademark, customer list, etc. (Tan and Low 2017). Furthermore, if CCs are mined, their assignment under the scope of IAS 38 would mean that they cannot be recognised as an asset at all. IAS 38.51 requires that an entity apply the requirements and guidance in paragraphs

\footnotetext{
${ }^{9}$ However, ECB (2015) defines digital currency as a digital representation of value, not issued by a central bank, credit institution or e-money institution, which, in some circumstances, can be used as an alternative to money. Such a definition is everything other than a strict refusal of CCs as money which is stipulated throughout the entire text of the ECB`s position paper.
} 
IAS38.52-67 to all internally generated intangible assets, though no entity can prove the fulfilment of all 6 conditions for the development phase of IAS38.57. The explanation rests on the nature of the mining procedure which is based on the "winner takes all" principle. For the reasons outlined, recognising CCs as intangibles is neither appropriate for externally purchased CCs, nor for mined CCs. Despite CCs "technically" meeting the definition of an intangible asset according to IAS 38, they do not possess the economic characteristics of intangible assets, in a way presumed as by IASB, when developing the standard. The issue of CCs may, thus, require a future redefinition of an intangible asset in an IFRS setting.

\section{DISCUSSION OF MODELS}

Despite IFRS not containing any specific guidance of accounting for CCs, several models can be developed based on existing accounting treatments of elements similar to CCs. This procedure, which follows the general requirements on the selection of an accounting policy according to IAS 8, may result in a quite different impact on financial position and performance. An appropriate model is crucial to provide users with relevant information faithfully representing economic reality. The selection shall be determined with reference to the purpose of CC acquisition. A different accounting model is to be applied when CCs are used as a payment method, compared, for example, to investment purposes. A summary of the possible approaches and particular scenarios of CC acquisition is presented in Fig. 2.

If CCs are used as payment methods, then they shall be treated as "foreign currencies”, i.e., transactions shall be translated at a spot rate, and closing balances, if any, shall be restated at a closing rate. The gain or losses recognised at year-end shall be included in profit or loss. A cryptocurrency as a functional currency is also possible, but hardly probable under current business and market conditions.

The most interesting scenarios are when CCs are purchased to realise future capital gains from an expected increase in the market price. Basically, three models are available with reference to IFRS guidance on similar items: the historical cost model (with impairment testing), the fair value model through profit or loss, and the fair value model through other comprehensive income. 


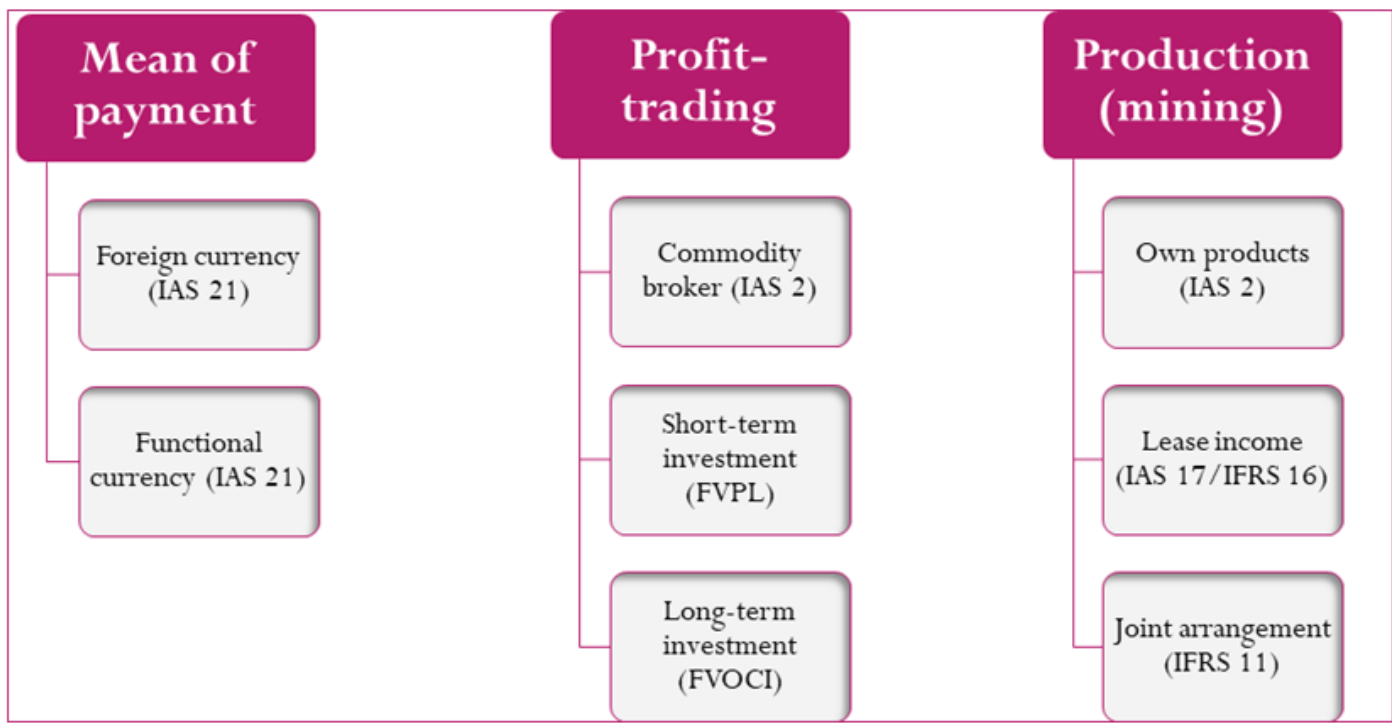

Figure 2. Accounting models for CCs under IFRS based on various motives

The survey of (Ram et al., 2016) shows that tensions between cost and fair value perceived by experts can be explained by the models grounded in stewardship and neoliberalism, respectively. The source of tensions comes from the differences in accounting treatment of market price fluctuations and all three models are outlined in Fig. 3.

Even though IAS 8 would allow an application of cost model, it can hardly depict the economic nature of investments into CCs faithfully (neither by trade-brokers, nor by "normal" investors). The assertion can be supported by the high volatility of market prices of CCs which precludes the historical cost model from providing useful information for users. Ignoring increases in the price of a CC over its acquisition costs magnifies the risks that users would not be capable of identifying the source of earnings persistency (Sloan, 1996), as the accrual and cash-flow components of performance are extremely different under historical cost model which reduces the magnitude of the accruals. 


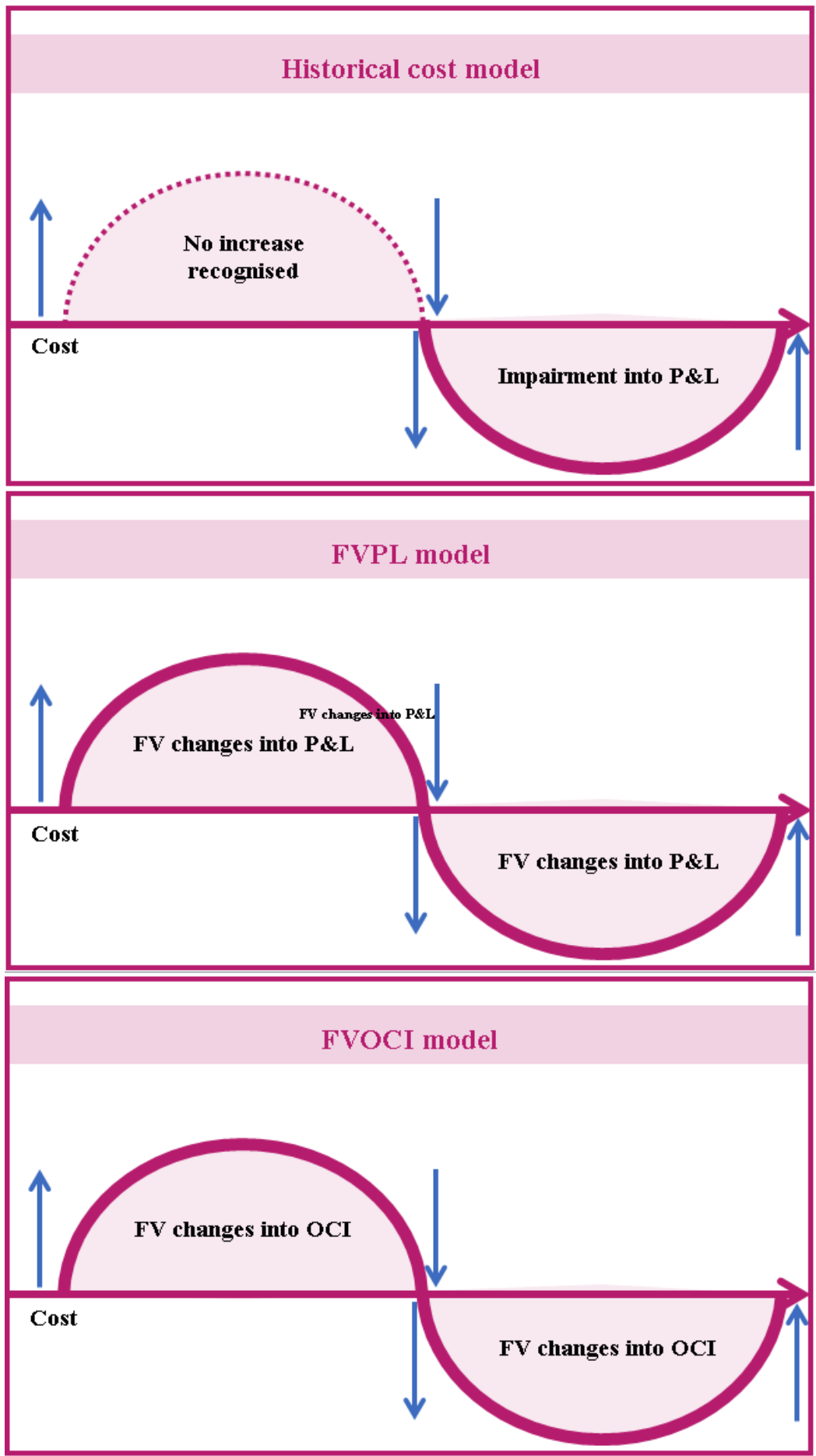

Figure 3. Measurement models for investments under IFRS 
As shown by Dechow and Weili (2006), high accrual firms have high earnings persistence relative to that of cash flows. Since cash flows and accruals of firms with high accruals are negatively correlated, the omission of fair value increases from an income statement can cause the misunderstandings related to the extent of the volatility of the business environment in which an entity operates and results, thus, in the mispricing of the entity's listed shares (Dechow and Weili, 2006).

To illustrate the magnitude of the issue, Fig. 4 shows the development of Bitcoin price (expressed in USD as closing daily values), as the main representative of cryptocurrencies, over a half-year period from 1 July 2017 to 15 February 2018. After a relatively stable oscillation around 3,500 USD over the first 6 weeks, the market price started to rise rapidly until mid-December 2017 when Bitcoin was trading for almost 19,500 USD. Subsequent market corrections sent the price to the local minima of 7,000 USD at the beginning of February followed by a "moderate" increase up to 10,000 USD in mid-February. The green lines in the chart denote the 25th and 75th percentile, the orange line indicates the median market price of Bitcoin over the presented period.

Fig. 4 reveals the abrupt changes in the market price of Bitcoin over the analysed period $^{10}$. To highlight the magnitude of the fluctuations, Fig. 5 compares the Bitcoin's market price movements with the development of the S\&P 500 index value over the same period. The changes in value of the S\&P500 index are negligible in contrast to the massive ups and downs of the Bitcoin price. The difference between the minimal and maximal value of the S\&P 500 index was 19.1 percentage points, with the largest positive daily change being $1.7 \%$ and the biggest drop being $4.3 \%$. The range between the minimum and maximum Bitcoin price reached 658.6 percentage points. The greatest day-to-day change was $20.2 \%$ (positive), or $27 \%$ (negative).

\footnotetext{
${ }^{10}$ The period could have been longer, and more cryptocurrencies could have been included. An exhaustive analysis is not the aim of this paper. The 6-month period used demonstrates and emphasises the extreme range of market price changes of Bitcoin (as the main representative of cryptocurrencies), even under a relatively short time frame. Such extreme fluctuations require special attention in financial reporting, e.g., by the application of mark-to-market accounting and by the recognition of changes in fair value.
} 


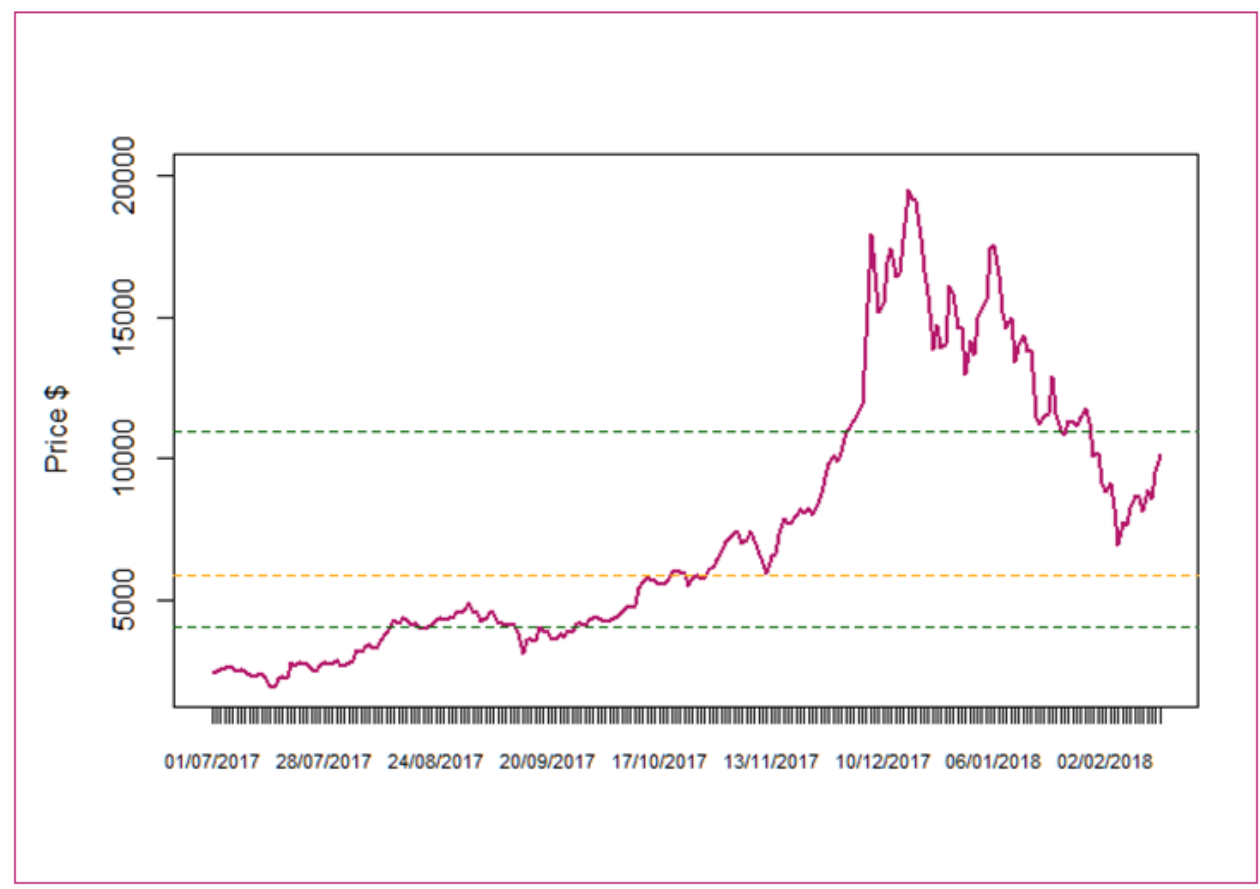

Figure 4. Market price of Bitcoin (in USD) from 01/07/2017 till 15/02/2018 ${ }^{11}$

To get more robust evidence of the relative volatility, both the Bitcoin and S\&P 500 time series are decomposed to eliminate the trend component and to extract the cycle component. In particular, the band-pass filtering developed by Baxter and King (1995) is applied. The results are presented in Fig. 6. The green lines represent the 25th and 75th percentiles. Even after eliminating the trend, the market value of Bitcoin is highly volatile throughout the analysed period. All relative price deviations of the S\&P 500 lie within the first and third quartile range. Such huge volatility needs to be addressed in accounting as well. All proposals of the application of cost model for the measurement of Bitcoin and other cryptocurrencies (either as inventory under IAS 2 or as an intangible asset under IAS 38) are unattainable from the perspective of decision-usefulness. Withholding information concerning the steep price increases and subsequent massive corrections prevents the users of financial statements from making qualified economic decisions.

\footnotetext{
${ }^{11}$ Author's illustration using R. Data from https://coinmarketcap.com/currencies/bitcoin/historical-data/ .
} 


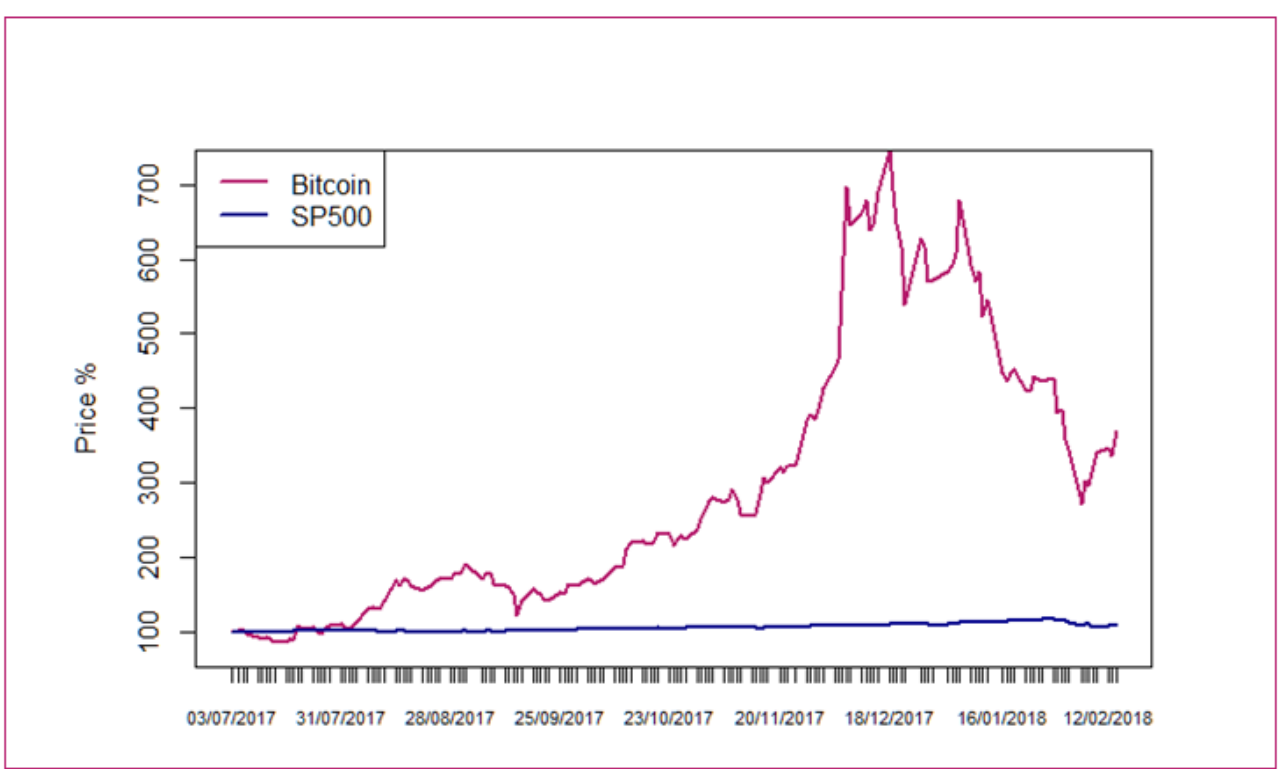

Figure 5. Bitcoin vs. S\&P 500 value comparison from 01/07/2017 till 15/02/2018 ${ }^{12}$

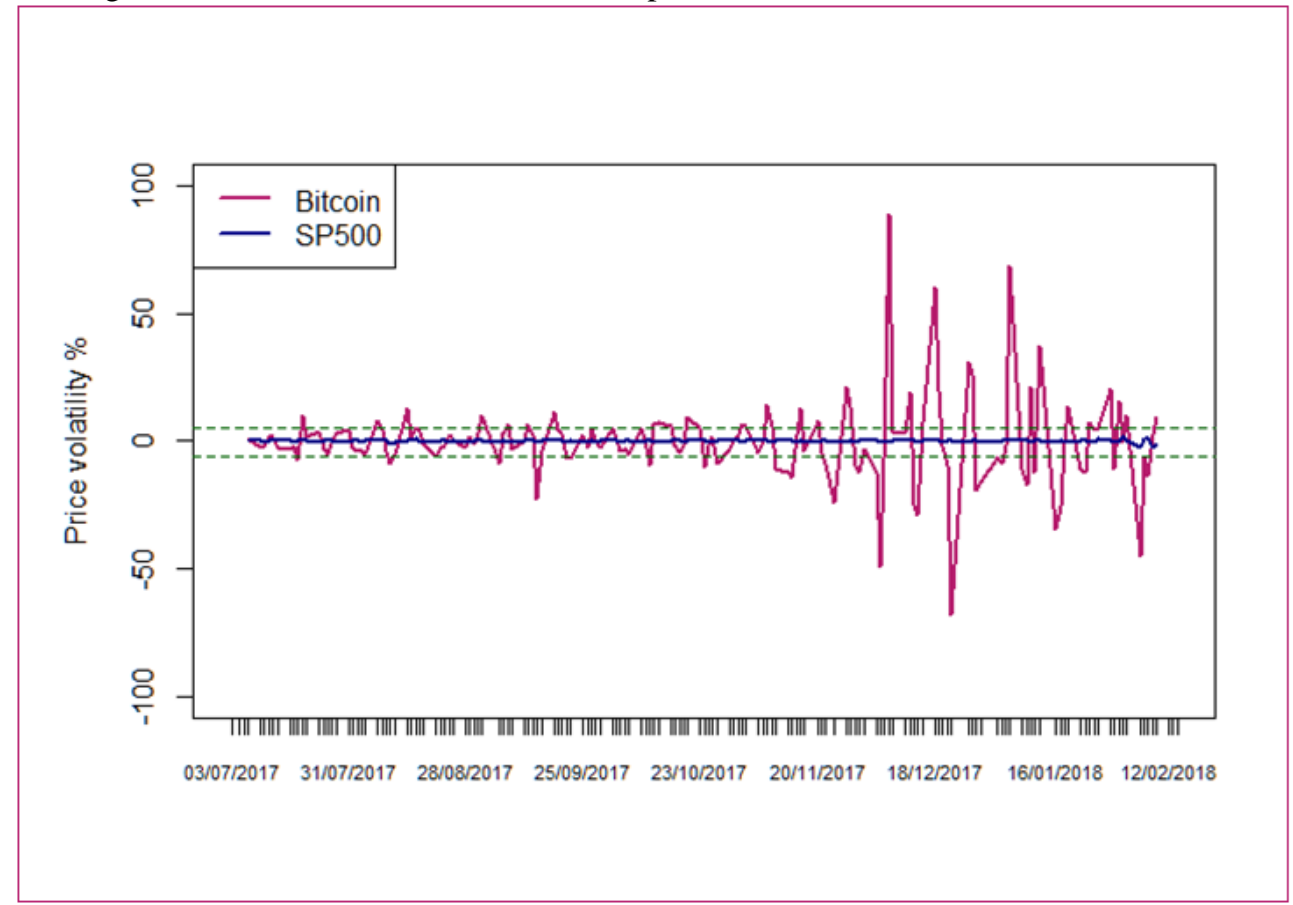

Figure 6. Bitcoin and S\&P 500 volatility from 01/07/2017 till 15/02/2018 ${ }^{13}$

\footnotetext{
${ }^{12}$ Author's calculations using R. Data from https://coinmarketcap.com/currencies/bitcoin/historical-data/ and https://finance.yahoo.com/quote/\%5EGSPC/history (value on 01/07/2017 = 100).

${ }^{13}$ Author's calculations using R, package mFilter. Note: Underlying data as in Figure 4.
} 
Mark-to-market accounting seems to be inevitable to provide relevant information to users if CCs are acquired and held for trading purposes. The logic of this assertion stems from the universal characteristics of fair value measurements, even under unstable economic conditions, and their usefulness in an investor's decision-making process (Hitz, 2007; Barth, 2007).

There was intensive debate about the role of fair value accounting in the financial crisis of 2007-2009. Opponents blamed fair value measurements from worsening the economic downturn because of its inherent procyclical nature multiplying the core changes in the business cycles (Novoa et al., 2009). Advocates assert that fair value accounting is just an innocent messenger of bad news (André et al., 2009). A summary of early arguments is assembled by (Procházka, 2011). Later empirical evidence provides arguments that fair value accounting is not procyclical (Amel-Zadeh et al., 2013). Furthermore, reliable measurements of fair values enhances the predictive value of accounting earnings (Bratten et al., 2016), as demonstrated on data from the 2007-2009 financial crisis when fair value adjustments predicted the future profitability of banks. Finally, fair value can also fit the stewardship purposes once information about fair values is combined (compared) with the respective information about historical cost (Rashad AbdelKhalik, 2010).

The studies analysed above document, both conceptually and empirically, that fair value accounting is irreplaceable when delivering useful information on financial instruments. Purchasing and selling CCs follows a similar pattern as investing into financial instruments or other investment instruments of a non-financial nature. The accounting treatment of cryptocurrencies, if they are acquired for short-term speculative or long-term investment purposes, shall therefore also refer to fair value measurement. A fair value model can also be justified by referring to the accounting treatment of short-selling CCs. As explained in Section 2.2, shortselling CCs meets the definition of a derivative contract and, as such, it shall be measured at FVPL. From the perspective of symmetry, it does not make any sense to have a different accounting treatment when the speculator expects an increase in price (traditional trading) or decrease in price (short-selling derivative) and fair value shall be applied for all transactions of investing/speculation nature.

There are two open issues when applying the fair value model: a) the presentation of fair value gains/losses - within PL or within OCI; b) the reliability of the 
measurement. The first issue relates to the general question of which level of income provides users with more useful information: net income (profit and loss) or total comprehensive income (including components of other comprehensive income)? Empirical studies provide mixed evidence on the value relevance of OCI components, depending on the context in which accounting information is used and how the income concept is defined (Rees and Shane 2012). Early evidence by (Dhaliwal et al., 1999) does not find any differences between either concept. On the other hand, (Biddle and Choi, 2006) show that comprehensive income dominates net income when explaining equity returns, but net income dominates comprehensive income when explaining executive compensation. The same conclusion regarding the superiority of comprehensive income on stock price and returns is confirmed by (Kanagaretnam et al., 2009) who also find that net income is a better predictor of future net income. As the importance of various levels of income statements differ in various contexts, a selection between the FVPL and FVOCI models for the presentation of changes in the market value of CCs shall be the same as under the guidance for financial instruments. If an entity invests into CCs with short-term (speculative, trading) purposes, all changes in fair value shall be reported within net income (profit and loss). If a longer investing perspective is taken, fair value changes shall be accounted for via other comprehensive income. Regardless of whether the FVPL or FVOCI model is applied, documented high price volatility constitutes a serious risk that reported financial position and performance will suddenly change to a significant extent. For this reason, extensive disclosures about all risks and an estimate of their impact under potential scenarios of future economic development shall be presented, e.g., in an analogous way as disclosures required by IFRS 7 on financial instruments and risk management.

The second unclear issue related to the usage of fair value accounting for CCs refers to the potentially low reliability of their market prices. There are two sources of unreliable measurements. Firstly, there is no active market for many CCs. According to the data of Coinmarketcap.com, the monthly trading volume of more than half of all CCs is under $\$ 1,000,000$. A low frequency of trading and insufficient number of willing sellers and buyers can contradict the conditions of IFRS 13 on Level 1 inputs in fair value hierarchy which means adjustments would need to be made. However, a deviation from quoted market prices, albeit in low active markets, may raise concerns of the users about the accuracy of mark-to- 
market measurement. Secondly, low market activity increases the risk of manipulation with the market price. As documented by (Gandal et al., 2018), a single market participant managed to manipulate the Bitcoin/USD exchange rate from $\$ 150$ to $\$ 1000$ in two months. Evidence of Bitcoin price manipulation, which is the biggest CC in terms of market capitalisation and trade volumes, indicates that unregulated cryptocurrency markets remain vulnerable to manipulation (Gandal et al., 2018). The significant risk of manipulation leading to an "unfair" market value can have negative consequences on the validity and precision of accounting measurements. However, the solution of this problem lies outside the boundaries defining the scope of financial reporting.

\section{CONCLUSIONS}

The paper assesses accounting models for cryptocurrencies under IFRS. The assessment is processed in two steps. Firstly, available models are defined using the general procedure of accounting policy choice described by IAS 8. As IASB has not resolved the issue yet, accounting treatments shall be derived with reference to similar transactions governed by existing standards. The exposition shows that there are several available methods based on the business model of the entity and the economic reality of the underlying transactions. Secondly, when competing models are possible for a certain type of transaction, these models are compared based on their expected decision-usefulness. Evidence from literature review, as well as recent time-series data on the price volatility of cryptocurrencies, indicate that fair value accounting is the most relevant source of useful information for the users of financial statements when cryptocurrencies are acquired for investment purposes. Furthermore, the paper identifies scenarios under which cryptocurrencies shall be treated as (foreign) currencies even though financial system regulators do not consider cryptocurrencies to be money.

The in-depth review of current IFRS accounting guidance shows that CCs are not treated by any specific standard or interpretation resulting in several challenges in classification and measurement. Depending on the purpose of acquisition, CCs can fall into multiple categories of assets, the majority of which are cash, inventory, and investment. However, CCs also meet the definition of an intangible asset, despite lacking the same economic characteristics as "standard" intangibles and such a classification could contradict their faithful representation in financial statements. The findings of this paper include several practical implications, in 
particular for regulators and users. Most of all, standard setters, such as the IASB, should commence work on the development of a new piece of guidance for accounting for cryptocurrencies. It could be reasonably expected that the extent of cryptocurrency usage within the daily business of firms will grow. In addition, cryptocurrencies are decentralised, unregulated, and may never be able to be regulate which may force central banks, state authorities or regulators to implement measures denying the economic substance of cryptocurrencies. At present, there are a considerable number of public pronouncements, preconceiving the accounting treatment of cryptocurrencies, which do not correspond to the nature of business transactions involving the acquisition or usage of cryptocurrencies. Under such circumstances, unharmonised accounting can endanger the ability of users to assess the financial position and performance of entities engaged in transactions with cryptocurrencies properly. Before best practice is established, the users of financial statements shall carefully inspect the notes to financial statements to ascertain whether an entity is involved in transactions with CCs, how these are recognised and measured and how financial statements are affected. However, even if a new standard is developed and best practice is established, CCs manifest serious risks. Does a company report all transactions with CCs? How can auditors identify the existence and the extent of transactions with CCs? How can their completeness be tested?

The study also has several limitations. Firstly, accounting research in the field is still in a nascent period of development, therefore literature review is not directed to the issue investigated, but to studies from related fields. Secondly, the assessment of competing models and their decision-usefulness rests on conceptual backgrounds of accounting literature, rather than on empirical evidence due to the lack of data. This restriction also leads to the suggestion of future research. Follow-up studies should investigate the accounting practices of companies using cryptocurrencies. The first phase is to focus on companies accepting cryptocurrencies as a means of payment, and the second phase should focus on companies investing into cryptocurrencies. Furthermore, accounting research should pay attention to the practices of (voluntary) disclosures concerning cryptocurrencies which may bring new insights into the informativeness of financial reporting and the interaction of standards and reporting incentives on accounting (disclosure) quality. 


\section{REFERENCES}

ACHESON, N. (2018): "How to Store Your Bitcoin". https://www.coindesk. com/information/how-to-store-your-bitcoins/

AMEL-ZADEH, A.; BARTH, M. E.; LANDSMAN, W. R. (2013): “Does Fair Value Accounting Contribute to Procyclical Leverage?” SSRN Electronic Journal. https://doi.org/10.2139/ssrn.2300497

ANDRÉ, P.; CAZAVAN-JENY, A.; DICK, W.; RICHARD, C.; WALTON, P. (2009): "Fair Value Accounting and the Banking Crisis in 2008: Shooting the Messenger”, Accounting in Europe, vol. 6, no. 1: 3-24. https://doi.org/10.1080/17449480902896346

BARTH, M. E. (2007): "Standard-Setting Measurement Issues and the Relevance of Research", Accounting and Business Research, vol. 37, no. Supplement 1: 715. https://doi.org/10.1080/00014788.2007.9730079

BAXTER, M.; KING, R. (1995): "Measuring Business Cycles Approximate Band-Pass Filters for Economic Time Series”. Cambridge, MA: National Bureau of Economic Research. https://doi.org/10.3386/w5022

BERCHOWITZ, G. (2017): “Accounting for Cryptocurrency”. http://pwc.blogs. com/ifrs/2017/11/accounting-for-cryptocurrency.html

BIDDLE, G. C.; CHOI, J. (2006): “Is Comprehensive Income Useful?”, Journal of Contemporary Accounting \& Economics, vol. 2, no. 1: 1-32. https://doi.org/10.1016/s1815-5669(10)70015-1

BRATTEN, B.; CAUSHOLLI, M.; KHAN, U. (2016): “Usefulness of Fair Values for Predicting Banks' Future Earnings: Evidence from Other Comprehensive Income and Its Components”, Review of Accounting Studies, vol. 21, no. 1: 280315. https://doi.org/10.1007/s11142-015-9346-7

BUNTINX, J. P. (2017): “What is a Bitcoin Broker?” https://themerkle.com/whatis-a-bitcoin-broker/

D’ALIESSI, M. (2016): “How Does the Blockchain Work?” https://medium.com/ @micheledaliessi/how-does-the-blockchain-work-98c8cd01d2ae

DECHOW, P. M.; WEILI, G. E. (2006): "The Persistence of Earnings and Cash Flows and the Role of Special Items: Implications for the Accrual Anomaly”, Review of Accounting Studies, vol. 11, no. 2-3: 253-296. https://doi.org/10.1007/s11142-006-9004-1

DHALIWAL, D.; SUBRAMANYAM, K.R.; TREZEVANT, R. (1999): “Is Comprehensive Income Superior to Net Income as a Measure of Firm Performance?”, Journal of Accounting and Economics, vol. 26, no. 1-3: 43-67. DOI https://doi.org/10.1016/s0165-4101(98)00033-0 
ECB (2015): Virtual Currency Schemes-A Further Analysis. Frankfurt am Main: European Central Bank. https://www.ecb.europa.eu/pub/pdf/other/virtual currencyschemesen.pdf

ECONOMICS REFERENCES COMMITTEE (2015): Digital Currency-Game Changer or Bit Player. The Australian Senate. https://www.aph.gov.au/ Parliamentary_Business/Committees/Senate/Economics/Digital_currency/ /media /Committees/economics_ctte/Digital_currency/report.pdf

GANDAL, N.; HAMRICK, J. T.; MOORE, T.; OBERMAN, T. (2018): "Price Manipulation in the Bitcoin Ecosystem", Journal of Monetary Economics, forthcoming. https://doi.org/10.1016/j.jmoneco.2017.12.004

GRECO, T. H. (2001): Money: Understanding and Creating Alternatives to Legal Tender. White River Junction: Chelsea Green Pub. ISBN 978-1-890132-37-8.

HAIG, S. (2018): “The Total Market Capitalization of All Cryptocurrency Markets Is Greater than That of Google”. https://news.bitcoin.com/totalcapitalization-of-the-crypto-markets-now-exceeds-750-billion/

HIGGINS, S. (2016): “Bitcoin Mining Firm KnCMiner Declares Bankruptcy”. https://www.coindesk.com/kncminer-declares-bankruptcy-cites-upcomingbitcoin-subsidy-halving/

HITZ, J. (2007): "The Decision Usefulness of Fair Value Accounting - A Theoretical Perspective”, European Accounting Review, vol. 16, no. 2: 323-362. https://doi.org/10.1080/09638180701390974

KANAGARETNAM, K.; MATHIEU, R.; SHEHATA, M. (2009): "Usefulness of Comprehensive Income Reporting in Canada”, Journal of Accounting and Public Policy, vol. 28, no. 4: 349-365. https://doi.org/10.1016/j.jaccpubpol.2009.06.004

KIYOTAKI, N.; WRIGHT, R. (1989): “On Money as a Medium of Exchange”, Journal of Political Economy, vol. 97, no. 4: 927-954. https://doi.org/10.1086/261634

MADEIRA, A. (2017a): “What is a Mining Pool?” https://www.cryptocompare .com/mining/guides/what-is-a-mining-pool/

MADEIRA, A. (2017b): "How to Choose and Connect to a Bitcoin Mining Pool?”. https://www.cryptocompare.com/mining/guides/choose-a-bitcoin-miningpool-and-how-to-connect/

MADEIRA, A. (2017c): “How Does Cloud Mining Work?” https://www. cryptocompare.com/mining/guides/how-does-cloud-mining-work/ 
MARTIN, W. (2018): "Sweden Could Be the First Economy to Introduce Its Own Cryptocurrency, Called the E-Krona”. http://www.businessinsider.com/swedencryptocurrency-e-krona-riksbank-2018-1

MCCABE, K. A. (1989): "Fiat Money as a Store of Value in an Experimental Market”, Journal of Economic Behavior \& Organization, vol. 12, no. 2: 215-231. https://doi.org/10.1016/0167-2681(89)90056-5

MISHKIN, F. S.; SERLETIS, A. (2011): The Economics of Money, Banking and Financial Markets. Toronto: Pearson Addison Wesley. ISBN 978-0-321-58471-7.

NAKAMOTO, S. (2008): "Bitcoin: A Peer-to-Peer Electronic Cash System”. https://bitcoin.org/bitcoin.pdf

NOVOA, A.; SCARLATA, J. G.; SOLÉ, J. (2009): “Procyclicality and Fair Value Accounting”. International Monetary Fund: Working Paper No. 09/39. https://www.imf.org/ /media/Websites/IMF/imported-full-text-

pdf/external/pubs/ft/wp/2009/_wp0939.ashx

PRICE, R. (2015): “The 21 Companies that Control Bitcoin”. http://uk.businessinsider.com/bitcoin-pools-miners-ranked-2015-7/\#21-unknownentity--01-1

PROCHÁZKA, D. (2011): “The Role of Fair Value Measurement in the Recent Financial Crunch", Prague Economic Papers, vol. 20, no. 1: 71-88. https://doi.org/10.18267/j.pep.388

RAIBORN, C.; SIVITANIDES, M. (2015): “Accounting Issues Related to Bitcoins”, Journal of Corporate Accounting \& Finance, vol. 26, no. 2: 25-34. https://doi.org/10.1002/jcaf.22016

RAM, A.; MAROUN, W.; GARNETT, R. (2016): “Accounting for the Bitcoin: Accountability, Neoliberalism and a Correspondence Analysis", Meditari Accountancy Research, vol. 24, no. 1: 2-35. https://doi.org/10.1108/medar-072015-0035

RASHAD ABDEL-KHALIK, A. (2010): "Fair Value Accounting and Stewardship”, Accounting Perspectives, vol. 9, no. 4: 253-269. https://doi.org/10.1111/j.1911-3838.2010.00013.x

REES, L. L.; SHANE, P. B. (2012): “Academic Research and Standard-Setting: The Case of Other Comprehensive Income”, Accounting Horizons, vol. 26, no. 4: 789-815. https://doi.org/10.2308/acch-50237

ROSIC, A. (2017): "What is Cryptocurrency: Everything You Need to Know”. https://blockgeeks.com/guides/what-is-cryptocurrency/

SHI, S. (1997): “A Divisible Search Model of Fiat Money”, Econometrica, vol. 65, no. 1: 75-102. https://doi.org/10.2307/2171814 
SLOAN, R. G. (1996): “Do Stock Prices Fully Reflect Information in Accruals and Cash Flows about Future Earnings?”, The Accounting Review, vol. 71, no. 3: 289-315.

SULLIVAN, K. (2016). "Working Towards a Common Accounting Framework for Gold”. World Gold Council. https://www.gold.org/download/file/5019/ Working_towards_a\%20common_accounting_framework_for_gold_updated_Jan 2018.pdf

TAN, B. S.; LOW, K. Y. (2017): "Bitcoin: Its Economics for Financial Reporting”, Australian Accounting Review, vol. 27, no. 2: 220-227. https://doi.org/10.1111/auar.12167 